\title{
The immunoglobulin $\kappa$ locus: polymorphism and haplotypes of Caucasoid and non-Caucasoid individuals
}

\author{
Gudrun Schaible ${ }^{1}$, Gudrun A. Rappold ${ }^{2}$, Walter Pargent ${ }^{1}$, Hans G. Zachau ${ }^{1}$ \\ ${ }^{1}$ Institut für Physiologische Chemie der Universität München, Schillerstrasse 44, D-80336 München, Germany \\ ${ }^{2}$ Institut für Humangenetik der Universität Heidelberg, Im Neuenheimer Feld 328, D-69120 Heidelberg, Germany \\ Hum Genet (1993) 91:261-267
}

The gene L25 in Fig. 1 belongs to subgroup III (not to II). 